\title{
El compromiso internacionalista. El Ejército de Liberación Nacional. Los elenos chilenos, 1966-1971. Formación e identidad
}

Pedro Valdés Navarro. Santiago: Lom Ediciones, 2018. 174 páginas.

Mario Vega Henríquez*

Esta interesante obra escudriña en una temática quizás poco difundida hasta ahora, como es la de un grupo de militantes del Partido Socialista de Chile (PS) que, desde mediados de la década de $1960 \mathrm{y}$, a partir del influjo de las ideas revolucionarias vigentes en su época, se conformaron como una corriente interna de éste, desarrollando acciones de adhesión y de compromiso con procesos insurreccionales desarrollados en el Cono Sur. Lo anterior, de forma paralela a su activa participación en la vida interna de su orgánica política, siendo capaces de manifestar un importante nivel de versatilidad en su actuar a través de los específicos contextos que enfrentaron.

De este modo, el llamado "Ejército de Liberación Nacional (ELN)" fue también el resultado de la histórica heterogeneidad ideológica existente al interior del PS, la que, según al autor, alternaba una estrategia de reformismo democrático y una posición revolucionaria; dualidad que no impedía identificarlo con aquello que se ha denominado como "izquierda tradicional". Sin embargo, los debates existentes al interior de sus congresos dan cuenta de una aguda confrontación entre ambas visiones, como asimismo reflejan el impacto que en ellos tuvieron

Chileno. Profesor de Historia, Geografía y Educación Cívica, Universidad Metropolitana de Ciencias de la Educación. Magíster en Educación, Universidad Academia de Humanismo Cristiano, Chile. Programa de Magíster en Historia de América Latina, Universidad Academia de Humanismo Cristiano, Chile. E-mail: mvegah@alumnos.academia.cl 
acontecimientos de la coyuntura nacional y regional, determinando en gran medida las orientaciones políticas establecidas.

A fin de otorgar un adecuado marco de comprensión para el sujeto histórico propuesto, el autor indaga en el especial impacto causado por la Revolución cubana sobre la izquierda chilena, como también en los singulares y tempranos lazos de cercanía entre Fidel Castro y Salvador Allende, como con su entorno familiar y partidario. Todo esto en contraste con la relativa distancia con que asume tal proceso el Partido Comunista, más bien partidario de un avance gradual dentro del marco institucional existente, el que, en lo fundamental, fue menos sensible a alterar tal definición estratégica.

En particular, no solo la experiencia antillana sino la imagen legendaria de sus íconos, como la del propio Ernesto Che Guevara y su acción insurgente en diversas luchas de liberación nacional en el Tercer Mundo durante aquellos años, resultan extraordinariamente llamativas para algunos militantes socialistas, incómodos a esas alturas con los marcos de acción convencionalmente asumidos por su partido. No obstante, la celebración del XXII Congreso de Chillán, en 1967, representó un significativo giro en las posiciones adoptadas, siendo plasmadas en sus resoluciones, representando una creciente influencia de los sectores más radicales al interior de partido y, sin duda, como parte de la onda expansiva de la Revolución cubana. De igual manera, las nuevas tesis generaron un marco para la intervención de los elenos chilenos en el foco guerrillero, levantado por su contraparte boliviana, liderada por Chato Peredo, como la manifestación de su compromiso internacionalista.

Al respecto, esta investigación recoge fundamentos para tal acción, ya en el marco de la intentona revolucionaria a nivel continental, articulada a través desde la Organización Latinoamericana de Solidaridad (OLAS), y en otros históricos precedentes, como la participación de chilenos en carácter de voluntarios a favor de la Independencia de Cuba, en 1898, y en la incorporación de militantes en las Brigadas Internacionales durante la Guerra Civil española.

En tal sentido, esta trayectoria nos podría mostrar, a simple vista, la radicalidad propia de una tendencia partidaria que abrazó una alternativa abiertamente divergente. A pesar de ello, el autor confronta 
este actuar con la posición adoptada por los elenos tras su retorno a Chile y su incorporación al gobierno de la Unidad Popular a partir de 1970, proyecto al que contribuyeron participando en los dispositivos de seguridad e inteligencia organizados desde la Presidencia, es decir, aportando el acervo de experiencias obtenidas en la insurgencia, no para promover esta alternativa, sino para actuar a partir de las instituciones, asumiendo una posición de mayor convergencia con la línea de su partido.

Esta trayectoria tensiona nuevamente las categorías de análisis establecidas para comprender a las izquierdas dentro del mencionado contexto histórico, y lo hace ya que el llamado "compromiso militante" se establece como un patrón superior que admite la adscripción de los elenos a tareas en apariencia contradictorias, pero que persiguen un mismo afán revolucionario.

Se trata entonces de la historia no solo de una corriente interna y de una posición ideológica. Por sobre ella, se encuentra la presencia de sus protagonistas, de sus fracasos y recomienzos, de su subjetividad revolucionaria y acción militante. De este modo, Pedro Valdés indaga en este protagonista colectivo, un círculo cercano al centenar de integrantes, liderado por Elmo Catalán, Arnoldo Camú, Carlos Lorca y Beatriz Allende, entre otros, organizados en distintas ciudades de Chile que, según el autor, "entre 1969 a 1971 alcanzaron su momento de mayor desarrollo" (p. 122), logrando transformarse en una influyente y emblemática facción de su partido.

La fidelidad de los elenos con el gobierno de Allende quedó demostrada en su ausencia en los encuentros que dieron forma a la Junta Coordinadora Revolucionaria (JCR), cuyos diálogos iniciales tuvieron lugar durante 1972 y que configuraron la estructura que permitiría a la nueva izquierda sumar esfuerzos y cooperación a nivel regional ante el avance de las intervenciones militares en el Cono Sur.

Por el contrario, septiembre de 1973 constituyó un duro epílogo para los elenos. Llamados a organizar focos de resistencia armada ante el golpe de Estado, de un modo disperso y con un limitado alcance en los cordones industriales, su resistencia fue fugaz. La asonada militar fue el hecho que los posicionó nuevamente como insurgentes en defensa de un fallido proceso de transformación socialista por la vía 
institucional y otorgó coherencia a su trayectoria. En tal sentido, cabe preguntarse, a la luz de lo expuesto en esta obra, si se trató de una organización sencillamente testimonial o que verdaderamente aspiró a ejercer influencia política al interior de la conducción de su partido.

En tal sentido, el autor realiza interesantes hallazgos que otorgan valor a la obra, al proponernos nuevas y sugerentes hipótesis respecto de este intenso periodo de la historia de nuestra región, otorgando nueva validez a su análisis. Ejemplo de ello lo encontramos en el diálogo que los elenos son capaces de articular con orgánicas revolucionarias en un nivel continental, desde un proyecto político que, más allá de su retórica, persevera en la opción electoral.

El autor nos muestra, a partir del análisis de las fuentes, un contexto en el que las hasta ahora rígidas categorías establecidas de izquierda tradicional y de nueva izquierda, fundamentales para comprender los procesos revolucionarios en América Latina a partir de la década de los sesenta, se vuelven difusas y se superponen en el caso específico del sujeto analizado. Lo anterior porque la trayectoria del ELN no representa un mero tránsito o derivación ideológica entre dos posiciones, sino más bien un "inusual fenómeno político" (p. 167) reflejado en la dualidad manifestada por un grupo insurgente al interior de un partido reformista. En tal sentido, la obra de Pedro Valdés posee el mérito de complejizar los enfoques hasta ahora utilizados para indagar las trayectorias de la izquierda en Chile, a la luz de las tensiones generadas por la Guerra Fría en el continente.

Esta obra rescata una dimensión de nuestro pasado en la perspectiva de lo que se ha denominado "Nueva Historia Política", la que pretende "rescatar las motivaciones y los sentidos de la acción política" (Ulianova, 2009: 11). En este caso, esta tarea se realiza sobre la base de trazas de un "pasado suspendido" (Augé, 1998: 66), tal vez idealizado por sus protagonistas, pues en él se encuentra el núcleo de su identidad de sus solidaridades y de sus mitos fundantes.

Lo anterior supone un interesante desafío en lo epistemológico y heurístico. Como mencionamos anteriormente, dada la naturaleza de este tipo de organizaciones, especialmente de aquellas que intervinieron en escenarios tan marcadamente simbólicos en el imaginario revolucionario como Nancahuazú y Teoponte, su documentación es 
reducida y sus acciones estaban compartimentadas, debido a razones de estricta seguridad.

Por su otra parte, los valiosos testimonios orales obtenidos por el autor requieren un primer esfuerzo para romper el cierto hermetismo existente sobre esta experiencia y ser contrastados con otras fuentes. Tales estrategias son en esta investigación uno de los recursos que permiten hacer aflorar un relato que vincula lo experiencial y lo analítico. A pesar de ello, no se trata de una obra testimonial, sino de una acertada operación historiográfica, lograda mediante una importante diversidad de referentes de información, que permiten a su autor sostener una interpretación propia, así como abordar las complejas aristas de la problemática planteada.

\section{Referencias Bibliográficas}

Augé, M. (1998). Las formas del olvido. Barcelona: Gedisa.

Ulianova, O. (2009). Redes políticas y militancias: la historia política está de vuelta. Santiago: Ariadna Ediciones-USACH. 